\title{
Evaluation of Boundary Dam Spillway Using an Autonomous Sensor Fish Device
}

ZD Deng*a ${ }^{\mathrm{a}}$,JPDuncan ${ }^{\mathrm{a}}$, JLArnold ${ }^{\mathrm{a}}, \mathrm{T}_{\mathrm{Fu}}^{\mathrm{a}}$, J Martinez ${ }^{\mathrm{a}}$, J Lu ${ }^{\mathrm{a}}$, PS Titzler ${ }^{\mathrm{a}}$, D. Zhou ${ }^{\mathrm{a}}$, RPMueller ${ }^{\mathrm{a}}$

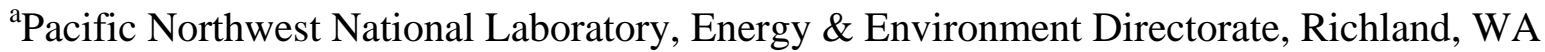
99352, United States

*Corresponding author. Tel.: +1 5093726120

E-mail address: Zhiqun.deng@pnnl.gov

\begin{abstract}
Fish passage conditions over spillways are important for the operations of hydroelectric dams because spillways are usually considered as a common alternative passage route to divert fish from the turbines. The objectives of this study were to determine the relative potential of fish injury during spillway passage both before and after the installation of baffle blocks at Boundary Dam, and to provide validation data for a model being used to predict total dissolved gas levels.Sensor Fish were deployed through a release system mounted on the face of the dam in the forebay. Three treatments, based on the lateral position on the spillway, were evaluated for both the baseline and post-modification evaluations: Left Middle, Right Middle, and Right. No significant acceleration events were detected in the forebay, gate, or transition regions for any release location; events were only observed on the chute and in the tailrace. Baseline acceleration events observed in the chute region were all classified as strikes, whereas postmodification events included strike and shear on the chute. While the addition of baffle blocks increased the number of severe events observed on the spillway chute, overall fewer events were
\end{abstract}


observed in the tailrace post-modification. Analysis of lateral positioning of passage indicated that the Right Middle treatment was potentially less injurious to fish based on relative frequency of severe events at each location. The construction of baffle blocks on the spillway visibly changed the flow regime. Prior to installation the flow jet was relatively thin, impacting the tailrace as a coherent stream that plunged deeply, possibly contributing to total dissolved gas production. Following baffle block construction, the discharge jet was more fragmented, potentially disrupting the plunge depth and decreasing the time that bubbles would be at depth in the plunge pool. The results in this study support the expected performance of the modified spillway chute: the addition of the baffle blocks generally lessened the depth and impact of entry.This study provides information that can be used to help design and operate spillways for improving fish passage conditions.

Keywords: Spillway; Environmental flow; Total dissolved gas; Hydroelectric dam; Fish passage.

\section{Abbreviations}

3D

CFD

g

GW

$\mathrm{Hz}$

$\mathrm{km}$

$\mathrm{kPa}$

LED

LSPIV
Three-dimensional

Computational Fluid Dynamics

Gravitational Acceleration

Gigawatt

Hertz

Kilometer

Kilopascal

Light Emitting Diode

Large-Scale Particle Image Velocimetry 
LM

m

$\mathrm{mm}$

MSL

MW

PNNL

R0

RF

$\mathrm{RM}$

S

TDG
Left Middle Deployment Location

Meter

Millimeters

Mean Sea Level

Megawatt

Pacific Northwest National Laboratory

Right Deployment Location

Radio Frequency

Right Middle Deployment Location

Seconds

Total Dissolved Gas 


\section{Introduction}

Hydropower is one of the largest renewable energy resources in the world,producing approximately 16.6\% of global electricity and 72.8\%of renewable electricity in 2014 (Ren21, 2015). While it is an established industry, it is still growing at a large scale compared to other renewable sources. Hydropower has a total global capacity of approximately 1,055 GW from 150 countries with 37 GW capacity added in 2014 (Ren21, 2015). Although hydropower offers many economic and environmental advantages, hydropower dams have potential adverse ecological impacts to fish passage, water quality, and habitat (Cada, 2001).

Downstream migrating fish maybe injured or killed by several possible mechanismsasthey pass through turbine routes (Cada, 2001): rapid and extreme pressure changes, cavitation, shear stress, turbulence, strike, and/or grinding. Therefore, alternative passage routes have beeninstalled to divert migrants over spillways or through bypass systems(Weber et al., 2006).A common method usedto bypass fish at small to medium sized hydroelectric plants uses screens as barriersto prevent fish from entering turbines, guiding fish throughadjacent passage routesduring their migration (Larinier, 2008; Larinier and Travade, 1999).Some keltsand smoltshave been observed to select spillways as their migration route ratherthan turbine passage(Arnekleiv et al., 2007).

Spill passage is usually regarded as the most benign downstream migration route for juvenile salmonids (Schilt, 2007).However, large spillway discharges have been known toproduce high (supersaturated) levels of dissolved gases in downstream rivers(Schilt, 2007), which can stress or kill fish because of gas bubble disease (Lutz, 1995; Backman and Evans, 2002), reduce swimming performance (Sciewe, 1974) and resistance to pathogens (Weiland et al., 1999), and affect spawning (Geist et al., 2013).Effortshave been devoted todam physical modifications to 
reduce dissolved gas generation requiring aquantitative understanding of the relationship between river hydrodynamic conditions and the dissolved gas levels encountered by fishes(Urban et al., 2008).In an effort to minimize the supersaturation of dissolved gases, spillway flow deflectors have been installed in several dams, and their impacts on the flow fields were investigated byan anisotropic two-phase flow model based on mechanistic principles (Politano et al., 2009). In addition, the flow fields upstream of a high dam in China under different intake and spillway operation patterns were investigated by using both numerical and experimental methods(Huang et al., 2015). Large-Scale Particle Image Velocimetry (LSPIV), as an extension of a quantitative imaging technique, was applied successfully to obtain surface flow velocities in the context of river and dam engineering projects(Kantoush et al., 2011). The Clean Water Act (33 U.S.C. § 1341 et seq.) and the Revised Code of Washington (RCW 90.48) require conformance with Washington State water quality standards and pollution prevention obligations. Water quality standards specify that Pend Oreille River total dissolved gas (TDG) concentrations shall not exceed 110 percent of saturation at any point of sample collection. TDG production at Boundary Dam, located on the Pend Oreille River, has been a concern to Seattle City Light since 1999. Research and field studies analyzing TDG abatement alternatives have been explored in efforts to mitigate any issues. Alternatives considered included throttle sluice gates, roughening sluice flow, and providing spillway flow splitters/aerators.

Baffle blocks have been designed for different engineering purposes. Reduced-scale evaluations have been conducted to evaluate the effects ofsemi-circular baffle blocks downstream of a Fayoum type weir (Abdelhaleem, 2013). Experimental investigations have also been conducted to optimize stilling basin influences using a shallow-water cushion for low Froude number energy dissipation (Li et al., 2015). Assessments involving computational fluid dynamics (CFD) 
and physical modeling contributed to Seattle City Light's decision to add baffle blocks at the end of Boundary DamSpillway 2. The baffle blocks were designed to break up the flow jet sufficiently to disrupt the depth of plunge and decrease the time that bubbles are at depth in the plunge pool, reducing TDG potential.

The objectives of this study were to determine the fish passage conditions of Boundary Dam Spillway 2 under both baseline (prior to modifications) and post-modification conditions and to provide validation data for a model being developed to predict total dissolved gas levels. Autonomous Sensor Fish were used to collect passagedata to establish a baseline assessment in 2014 and to evaluate post-modification conditions in 2015 (after the installation of the baffle blocks). Significant acceleration events were identified and classified as strike or shear, based upon the acceleration magnitude impulse. The plunging depth of Sensor Fish in the tailrace was also calculated to assess the effect of the added baffle blocks on jet dispersion.

\section{Methods}

\subsection{Study Site}

Boundary Dam, operated by Seattle City Light, is located at river kilometer 27 on the Pend Oreille River, about 16 km north of Metaline Falls, Washington, and just south of the US-Canada border (Figure 1). It is a concrete arch gravity-type dam, $225 \mathrm{~m}$ long and $103 \mathrm{~m}$ high. Normal pool elevation is $607 \mathrm{~m}$ above mean sea level (MSL). It has six Francis turbines, with a total generating capacity of approximately $1040 \mathrm{MW}$, and two spillways, each $15 \mathrm{~m}$ wide with a $14 \mathrm{~m}$ long radial gate. Spillway No.2 is on the right abutment looking downstream. The spillway crest is at elevation $594 \mathrm{~m}$ above MSL. Maximum discharge capacity through the two spillways is $3058 \mathrm{~m}$ /s. Plunge distance to the immediate tailrace is approximately $55 \mathrm{~m}$, dependent upon 
tailwaterelevation.Nine baffles were installed in 2014, each with a $1.5 \mathrm{~m}$ by $1.2 \mathrm{~m}$ face (Figure 2).The baseline evaluation was conducted prior to modification. The post-modification evaluation was conducted after chute modification, examining the effects of the newly installed baffle-blocks on the flow, and possible impact on fish passage over the spillway.

\subsection{Sensor Fish Device}

The Sensor Fish, powered by a rechargeable battery, is $24.5 \mathrm{~mm}$ in diameter and $89.9 \mathrm{~mm}$ long (Figure 3; Deng et al., 2014). It contains three-dimensional (3D) rotation sensors (i.e., 3-axis gyroscope), 3D linear acceleration sensors (i.e., 3-axis accelerometers), a pressure sensor, a temperature sensor, a 3D orientation sensor (i.e., 3-axis magnetometer), a radiofrequency (RF) transmitter, a recovery module, and a communication module. Its mass is approximately $42.1 \mathrm{~g}$, and is neutrally buoyant in fresh water at deployment, with size and density similar to those of a yearling salmon smolt. The Sensor Fish components are placed such that the center of gravity is very close to the geometric center. A low-power microcontroller collects data from the sensors and stores up to 5 minutes of data on an internal non-volatile flash memory at a sampling frequency of 2,048 Hz. The recovery module makes the Sensor Fish positively buoyant, bringing the unit to the water's surface for recovery after a pre-programmed time. All of the sensors, including the pressure sensor, accelerometers, three-axis gyroscope, magnetometer, and temperature sensor were calibrated and evaluated individually prior to field use.

\subsection{Data acquisition}

For ease of recovery the Sensor Fish were also equipped with a micro-radio transmitter (ATS, Isanti, Minnesota) and a balloon tag (made in house) for visual detection. The balloon tags contain a capsule filled with non-toxic chemicals. Gas is produced when the capsule dissolves allowing the chemicals to react,inflating the balloons and buoying the unit to the surface. A 
directional radio receiver antenna was used to locate the radio transmitter, aiding in the Sensor Fish recovery. The Sensor Fish also contains onboard Light Emitting Diodes (LEDs) that flash after data acquisition has completed, allowing for visual identification in low-light conditions.

Both the baseline and post-modification evaluations examined passage at three lateral positions on the spillway, designated Left Middle (LM), Right Middle (RM), and Right (R0). Left and right are oriented looking downstream. Passage via LM was directed at a baffle in the front row of baffles, RM was directed at a baffle in the back row of baffles, and R0was designed to pass between the wall and baffles on the far right side (Figure 4).Sensor Fish were deployed through a release system, which was constructed of structural steel piping and erected using steel plating attached to dam structure. The Sensor Fish were placed into the pipe on deck and flushed through the pipe to exit at approximately $594 \mathrm{~m}$ above MSL, just in front of the spillway crest. A total of 48 valid datasets collected for the baseline evaluation on July 20, 2014 and 81 valid datasets were acquired for the post-modification evaluation on March 28 and 29, 2015 (Table 1).

\subsection{Data analysis}

Sensor Fish data analysis included reviewing time histories for all Sensor Fish datasets, which consist of pressure, acceleration (x, y, and $\mathrm{z}$ axes), rotational velocity (pitch, roll, and yaw), and temperature. Pressure data were used to estimate Sensor Fish depth and to identify characteristic signatures and timing marks that allowed passage regions to be identified. Timing marks,created to identify regions of spillway passage and to positionsevere events include: 1) Exit from the injection system(release pipe); 2) Passage under the tainter gate; 3) Passage along the spillway chute; 4) Passage in air prior to plunge into tailrace (designated as transition); 5) Plunge into tailrace; 6) Tailrace passage. 
To qualify as a severe event, a high-amplitude acceleration impulse must have a peak value equal to or greater than $95 \mathrm{~g}$. The threshold of $95 \mathrm{~g}$ was established from laboratory tests where both juvenile salmonids and Sensor Fish were exposed to shearing flows (Richmond et al. 2009) and at this value there was a nearly $100 \%$ probability of minor injury. The acceleration events are counted by first identifying spikes in the acceleration magnitude data that exceed $25 \mathrm{~g}$ and are more than $0.00375 \mathrm{~s}$ from a nearby spike (keeping larger value). These spikes in the acceleration magnitude data are then categorized into different levels, where the severe events correspond to those that exceed $95 \mathrm{~g}$. Finally the events are categorized as either being attributed to strike or shear. When $70 \%$ of the maximum amplitude of a severe event lasts less than $0.0075 \mathrm{~s}$, it is classified as a strike; when $70 \%$ of the maximum amplitude of the event is longer than $0.0075 \mathrm{~s}$, it is classified as shear. More detailed information on the data analysis can be found at Deng et al. (2007 and 2010).

The depth attained upon entry into the tailrace was calculated from Sensor Fish pressure measurements, assuming hydrostatic pressure. The comparison of the depth and impact magnitude between baseline and post-modification conditions was conducted using a modified Kolmogorov-Smirnov test under the null hypothesis of same continuous distribution (Conover, 1980).

\section{Results}

\section{1 Passage examples}

Figure 5shows thepressure,acceleration, and rotational data collected by a Sensor Fish from atypical passage duringthe baseline evaluation before the baffle block installation. The tailrace designation includes Sensor Fish entry into the plungepool and passage in the tailrace.An 
example of Sensor Fishpassage data from the post-modification evaluation after the installation of the baffle blocks is shown in Figure 6. While similar to the baseline condition, there is a noticeable increase in pressure on the chute as the flow is redirected by the baffle blocks. Sensor Fish interactions with the baffle blocks and the redirection and fragmentation of flow resulted in an increased time period while in the chute region. However, shorter transit times were observed from the entrance to gate and gate to chute regions, attributed to the higher flow $\left(340 \mathrm{~m}^{3} / \mathrm{s}\right.$ vs. $283 \mathrm{~m}^{3} / \mathrm{s}$ ) during the the post-modification evaluation (Table 2).

\subsection{Collision and Shear Events}

Severe events on a spillway are usually the result of collision with dam structure, or exposure to shear in flow. For both baseline and post-modification evaluations, no significant acceleration events were detected in the forebay, gate, or transition regions for any release location; events were only observed on the chute and in the tailrace. Ninety-two percent of the Sensor Fish released during the baseline evaluation experienced at least one severe event during passage, regardless of passage route. Severe events increased post-modification, except in the RM treatment, which decreased by $4 \%$. Table 3 summarizes the total number of Sensor Fish releases that contained at least one severe event (no distinction between releases with only one or multiple severe events) by severe event type and location for each treatment route.

Severe event magnitudes for the chute region increased following installation of the baffle blocks, regardless of lateral injection location (Table 4). There were no severe events prior to baffle block installation for the R0treatment group, and severe event magnitudes were similar, regardless of lateral location for each evaluation. Magnitudes of severe events in the tailrace were reduced, with the exception of the LM release location, which increased slightly, although not significantly. 


\subsection{Tailrace Entry}

Following passage over the chute and navigatingthe baffle blocks the Sensor Fish were carried through the air before plunging into the tailrace,approximately $55 \mathrm{~m}$ below. Impact with the water surface and maximum depth attained were examined using the first two seconds after entry for impacts, and the first 10 seconds after entry for depths (Table 5). These time intervals were chosen to allow for the sensors to compensate for the substantial aeration produced by the flow upon tailrace entry. For both the LM and RM treatments where the baffle blocks were designed to reduce the depth of entry in the tailrace, the post-modification condition has a significantly shallower depth of entry in the tailrace than the baseline condition with mean depth difference being $4.7 \mathrm{~m}$ and $10.2 \mathrm{~m}$ for LM (P-value $=0.003)$ and $\mathrm{RM}(\mathrm{P}$-value $<0.001)$, respectively. While the post-modification condition has significantly greater $(\mathrm{P}$-value $=0.029)$ depth of entry in the tailrace than the baseline condition for the R0 position, the mean depth difference was only 1.4 m, which was likely due the higher discharge of the post-modification condition. When all the treatments were pooled, the depths attained under post-modification conditionwere significantly (P-value $<0.001$ ) shallower than those under the baseline condition.This observation can be seen when comparing the pressures in the tailrace region between Figures 5 and 6.

The maximum observed Sensor Fish acceleration magnitude occurring within the first two seconds after entering the tailrace is reported as the impact magnitude (Figure 7). Impact magnitudes ranged from 59 to over $300 \mathrm{~g}$, with median impacts ranging from approximately 145 to $195 \mathrm{~g}$ during the baselineevaluation and 143 to $153 \mathrm{~g}$ for the post-modification condition.While the difference of the impact magnitude for each lateral location between the baseline andpost-modification conditions was not significant $(\mathrm{P}$-value $=0.854$ for LM; $\mathrm{P}$-value $=$ 0.404 for RM; P-value $=0.103$ for R0), the median impact magnitudes decreased by more than 
$40 \mathrm{~g}$ for RM (190 vs. $135 \mathrm{~g}$ ) and R (195 vs. $153 \mathrm{~g}$ ) locations and remained almost the same for LM (144 vs. 145 g)after installation of the of the baffle blocks. When all locations were pooled together, the difference ofimpact magnitude between them was not significant either $(\mathrm{P}$-value $=$ $0.248)$.

\subsection{Pressure Rate of Change}

The maximum rates of change in pressure during passage under the tainter gate at Spillway 2 were calculated from Sensor Fish pressure time histories (Figure 8). The maximum pressure rate of change was calculated using a 0.05-s period during the passage under the gate where pressure values decrease precipitously as the Sensor Fish approached atmospheric pressure. Observed pressure rate of change values were similar for the baseline and post-modification conditions, with the baseline treatments showing a slightly more rapid change, due to the smaller tainter gate opening.

\section{Discussion and Conclusions}

In efforts to reduce TDG production at Boundary Dam nine baffle blocks were added to the spillway chute. These baffle blocks contribute to the fragmentation ofthe flow jet, disrupting the depth of plunge which decreases the aeration at depth. The objective of this study was to describe and compare the baseline and post-modification passage conditions on Spillway 2 at Boundary Dam, contrasting conditions for three release locations and to determine the relative potential of fish injury due to these conditions using the Sensor Fish. Figure 9illustrates the differences in the flow jet before and after baffle block construction. The flow jet was noticeably disrupted following spillway modification. 
For both the baseline and post-modification evaluations, the number of overall severe events ranged from $85 \%$ to $100 \%$ across all treatments. No events were observed in the forebay, gate, or transition regions for any release location; events were observed only on the chute and in the tailrace. The percentage of severe eventson the spillway chutewas increased after the baffle blocks were added, but the percentage of severe events in the tailrace was lower under the postmodification condition than the baseline condition.

TDG is increased when air bubbles are injected deep in the tailrace. Sensor Fish data suggest that the impact and depth of entry into the Boundary Dam tailrace were lessened by the addition of baffle blocks on the spillway chute, supporting the assumption that TDG may be reduced. Median impacts were observed to decrease for Sensor Fish passage through the R0and RM treatment locations; however, there was a slight increase observed for the LM treatment location, although the impacts were close in magnitude (144 and $145 \mathrm{~g}$, for the baseline and postmodification, respectively). The LM and RM treatment locations saw a significant decrease in mean depth upon entry into the pool after the baffle blocks were added, while the R0treatment location had a slight increase in plunge depth. A possible explanation for this may be that the R0location is less likely to interact with the baffles, which could allow the flow during that treatment to plunge more deeply, if not as energetically. In addition, the post-modification evaluation had a larger flow rate than baseline evaluation $\left(340 \mathrm{~m}^{3} / \mathrm{s}\right.$ vs. $\left.283 \mathrm{~m}^{3} / \mathrm{s}\right)$.

The pressure rate of change under the gate to the spillway chute, characterizes the change from the forebay pool to atmospheric pressure. While similar, the rates observed for the baseline condition were slightly greater than those observed for the post-modification evaluation, due to the lower gate opening. The gate was open approximately $2.3 \mathrm{~m}$ during the baseline evaluation 
and approximately $2.4 \mathrm{~m}$ post-modification. This slight difference in opening would create a higher pressure behind the gate, dependent on the forebay levels. Pressure rates of change observed during the Boundary Dam evaluations were similar for the LM and R0treatment locations; however, a difference was observed for the RM treatment location, with a significantly lower pressure rate of change observed during the post-modification evaluation. Observed pressure rates of change at Boundary Dam were relatively low, ranging between 372 and 455kPa/s. Pressure rates of change for passage under tainter gates on Columbia and Snake River dams have been observed to be greater than 2,758kPa/s at John Day Dam (Duncan, 2011) and between 345 and 1,896kPa/s at Ice Harbor Dam (Carlson et al., 2008).

While Sensor Fish studies have been performed at other dams on major rivers in the northwest, none of the spillways evaluated have been comparable to the conditions experienced at Boundary Dam. Both the incline and length of the spillway at Boundary are lower, and the plunge into the tailrace from the spillway is unique. A Sensor Fish study conducted at Detroit Dam on the North Santiam River in Oregon evaluated passage through a regulating outlet (RO), which included an approximate $34 \mathrm{~m}$ plunge into a tailrace (Duncan and Carlson, 2011). The Detroit Dam evaluation focused on passage through two RO gate openings and not on the effects of the plunge; however, comparing the values obtained at Detroit Dam with those from Boundary provides a point of reference. Maximum plunge acceleration magnitudes ranged from approximately 130 to $181 \mathrm{~g}$ at Detroit Dam, most of which were shear events; maximum plunge magnitudes at Boundary Dam were greater than $270 \mathrm{~g}$. The distance to the tailrace at Boundary Dam ( 55 m) was almost twice of that at Detroit Dam, contributing to the higher observed acceleration magnitudes. 
Overall, the exposure conditions observed from Sensor Fish time histories following passage through spillway 2 at Boundary Dam indicate that the addition of baffle blocks to the spillway chute will likely reduce the TDG produced by spill flow into the tailrace. The reductionin TDG production would decrease the likelihood of gas bubble disease (Backman and Evans, 2002) and lead to a healthier habitat (Weiland et al., 1999; Geist et al., 2013). Sensor Fish impact magnitudes upon entry to the tailrace and depths attained following spillway modification were generally reduced, indicating that the flow jet was being disrupted sufficiently to not dive as deeply into the plunge pool. The results from this study can be help guide design and operations of spillways for improving fish passage conditions.

\section{Acknowledgements}

The study was conducted at Pacific Northwest National Laboratory (PNNL), operated by Battelle for the U.S. Department of Energy.The field data collection and data analysis was funded by Seattle City Light.Andrew Bearlinand James Lussman were the technical point of contacts.The Sensor Fish and related evaluation tools were funded by the U.S. Department of Energy Wind and Water Power Technologies Office. The Sensor Fish release pipe was designed by the engineering consulting company Hatch. We also thank Chick Sweeney and Shari Dunlop of Alden lab for their help with the design and coordination of this study and many staff members of PNNL for their support of the field deployment.

\section{References:}

- Abdelhaleem, F.S.F., 2013. Effect of semi-circular baffle blocks on local scour downstream clear-overfall weirs. Ain Shams Engineering Journal4(4), 675-684. 
- Arnekleiv, J.V., Kraabøl, M.,Museth, J., 2007. Efforts to aid downstream migrating brown trout (Salmo trutta L.) kelts and smolts passing a hydroelectric dam and a spillway. Hydrobiologia 582(1), 5-15.

- Backman, T.W.H., Evans, A.F., 2002. Gas bubble trauma incidence in adult salmonids in the Columbia River Basin. N. Am. J. Fish. Manage. 22, 579-584.

- Čada, G.F.,2001. The development of advanced hydroelectric turbines to improve fish passage survival. Fisheries26(9), 14-23.

- Carlson, T.J., Duncan, J.P.,Deng, Z., 2008. Sensor Fish Characterization of Spillway Conditions at Ice Harbor Dam in 2004, 2005, and 2006. PNWD-3839, Battelle Pacific Northwest Division, Richland, Washington.

- Conover, W.J., 1980, Practical Nonparametric Statistics. John Wiley \& Sons, New York, NY, USA.

- Deng, Z., Carlson, T.J.,Duncan, J.P., Richmond, M.C., 2007. "Six-Degree-of-Freedom Sensor Fish Design and Instrumentation." Sensors 7(12):3399-3415.

- Deng, Z., Carlson, T.J., Duncan, J.P., Richmond, M.C.,Dauble, D.D., 2010. Use of an Autonomous Sensor to Evaluate the Biological Performance of the Advanced Turbine at Wanapum Dam. Journal of Renewable and Sustainable Energy 2(5):053104.

- Deng, Z.D., Lu, J., Myjak, M.J., Martinez, J.J., Tian, C., Morris, S.J., Carlson, S.J.,Zhou, D.,Hou, H., 2014. Design and Implementation of a new Autonomous Sensor Fish to Support Advanced Hydropower Development. Review of Scientific Instruments 85(11):115001. doi:10.1063/1.4900543 
- Duncan, J.P., 2011. Sensor Fish Characterization of Fish Passage Conditions through John Day Dam Spillbay 20 with a Modified Flow Deflector. PNNL-20359, Pacific Northwest National Laboratory, Richland, Washington.

- Duncan, J.P.,Carlson, T.J., 2011. Characterization of Fish Passage Conditions through a Francis Turbine, Spillway, and Regulating Outlet at Detroit Dam, Oregon, Using Sensor Fish, 2009. PNNL-20365, Pacific Northwest National Laboratory, Richland, Washington.

- Geist, D.R., Linley, T.J., Cullinan, V., Deng, Z.,2013. The Effects of Total Dissolved Gas on Chum Salmon Fry Survival, Growth, Gas Bubble Disease, and Seawater Tolerance. North American Journal of Fisheries Management 33(1), 200-215.

- Huang, B., Zhu, D.Z., Shao, W., Fu, J., Rui, J., 2015. Forebay hydraulics and fish entrainment risk assessment upstream of a high dam in China. Journal of Hydro-environment Research 9(1), 91-103.

- Kantoush, S.A., Schleiss, A.J., Sumi, T., Murasaki, M., 2011. LSPIV implementation for environmental flow in various laboratory and field cases. Journal of Hydro-environment Research5(4), 263-276.

- Larinier, M., 2008. Fish passage experience at small-scale hydro-electric power plants in France. Hydrobiol 609, 97-108.

- Larinier, M., Travade, F., 1999. The development and evaluation of downstream bypasses for juvenile salmonids at small hydroelectric plants in France. In: Odeh, M. (Ed.), Fish Passage Technology. American Fisheries Society, Bethesda, MD.

- Li, L.X., Liao, H.S., Da, L.I.U., Jiang, S.Y., 2015. Experimental investigation of the optimization of stilling basin with shallow-water cushion used for low Froude number energy dissipation. Journal of Hydrodynamics, Ser. B 27(4), 522-529. 
- Lutz, D.S., 1995. Gas supersaturation and gas bubble trauma in fish downstream of a Midwestern reservoir. Trans. Am.Fish. Soc. 124, 423-436.

- Politano, M., Carrica, P., Weber, L.,2009. A multiphase model for the hydrodynamics and total dissolved gas in tailraces. International Journal of Multiphase Flow 35(11), 1036-1050.

- REN21, Paris Secretariat, 2015. Renewables 2011 global status report. Paris, France: REN21 Secretariat., see http://www.ren21.net/status-of-renewables/global-status-report/

- Richmond, M.C., Deng, Z., McKinstry, C.A., Mueller, R.P., Carlson, T.J., Dauble, D.D. 2009. Response Relationship Between Juvenile Salmon and an Autonomous Sensor in Turbulent Flows. Fisheries Research 97(1-2):134-139.Schilt, C. R., 2007. Developing fish passage and protection at hydropower dams. Applied Animal Behaviour Science104(3), 295325.

- Schilt, C.R., 2007. Developing fish passage and protection at hydropower dams. Applied Animal Behaviour Science, 104(3), pp.295-325.

- Sciewe, M.H., 1974. Influence of dissolved atmospheric gas on swimming performance of juvenile chinook salmon.Trans. Am. Fish. Soc. 103, 717-721.

- Urban, A.L., Gulliver, J.S., Johnson, D.W., 2008. Modeling total dissolved gas concentration downstream of spillways. Journal of hydraulic engineering 134(5), 550-561.

- Weber, L.J., Goodwin, R.A., Li, S., Nestler, J.M., Anderson, J.J. ,2006. Application of an Eulerian-Lagrangian-Agent method (ELAM) to rank alternative designs of a juvenile fish passage facility. Journal of Hydroinformatics 8(4), 271.

- Weiland, L.K., Mesa, M.G., Maule, A.G., 1999. Influence of infection with Renibacteriumsalmoninarum on susceptibility of juvenile spring chinook salmon to gas bubble trauma. J. Aquat. Anim. Health 11, 123-129. 


\section{List of Figures}

Figure 1. Location of Boundary Dam on the Pend Oreille River in Washington State.

Figure 2. Installed Baffle-blocks at Boundary Dam.

Figure 3. The Autonomous Sensor Fish Device: (a) CAD drawing; (b) Photograph.

Figure 4. Location of Sensor Fish Lateral Release Positions

Figure 5.Example of Sensor Fish Data Showing the Approximate Locations of Major Timing Marks during Baseline Passage (i.e., prior to baffle block installation). (a) Absolute pressure (blue) and acceleration magnitude (green); (b) Absolute pressure (blue) and rotational velocity magnitude (green). The Sensor Fish data was collected on July 20, 2014 at 7 pm from the Left Middle location.

Figure 6.Example of Sensor Fish Data Showing the Approximate Locations of Major Timing Marks during Post-Modification Passage (i.e., after baffle block installation). (a) Absolute pressure (blue) and acceleration magnitude (green); (b) Absolute pressure (blue) and rotational velocity magnitude (green). The Sensor Fish data was collected on March 28, 2015 at 6 pm from the Right Middle location.

Figure 7.Sensor Fish Impact Magnitudes uponEntry to the Tailrace. Three lateral positions are evaluated: Left Middle (LM), Right Middle (RM), and Right (R0).

Figure 8. Pressure Rate of Change for Passage under the Gate.Three lateral positions are evaluated: Left Middle (LM), Right Middle (RM), and Right (R0).

Figure 9. Spill Discharge at Boundary Dam: (a) On July 20, 2014 at 1:26 PM, prior to baffle block construction; (b) On March 28, 2015 at 10:32 AM, following baffle block construction (b). Following construction of the baffle blocks the flow jet was noticeably disrupted, potentially disrupting the plunge depth.

List of Tables

Table 1. Number of Sensor Fish Releases by Study Treatment

Table 2. Mean Sensor Fish Passage Time for Each Passage Region

Table 3. Number of Sensor Fish Releases with Severe events by Treatment

Table 4. Sensor Fish Significant Acceleration Events by Treatment 
Table 5. Sensor Fish Depths Attained upon Entry into Tailrace 


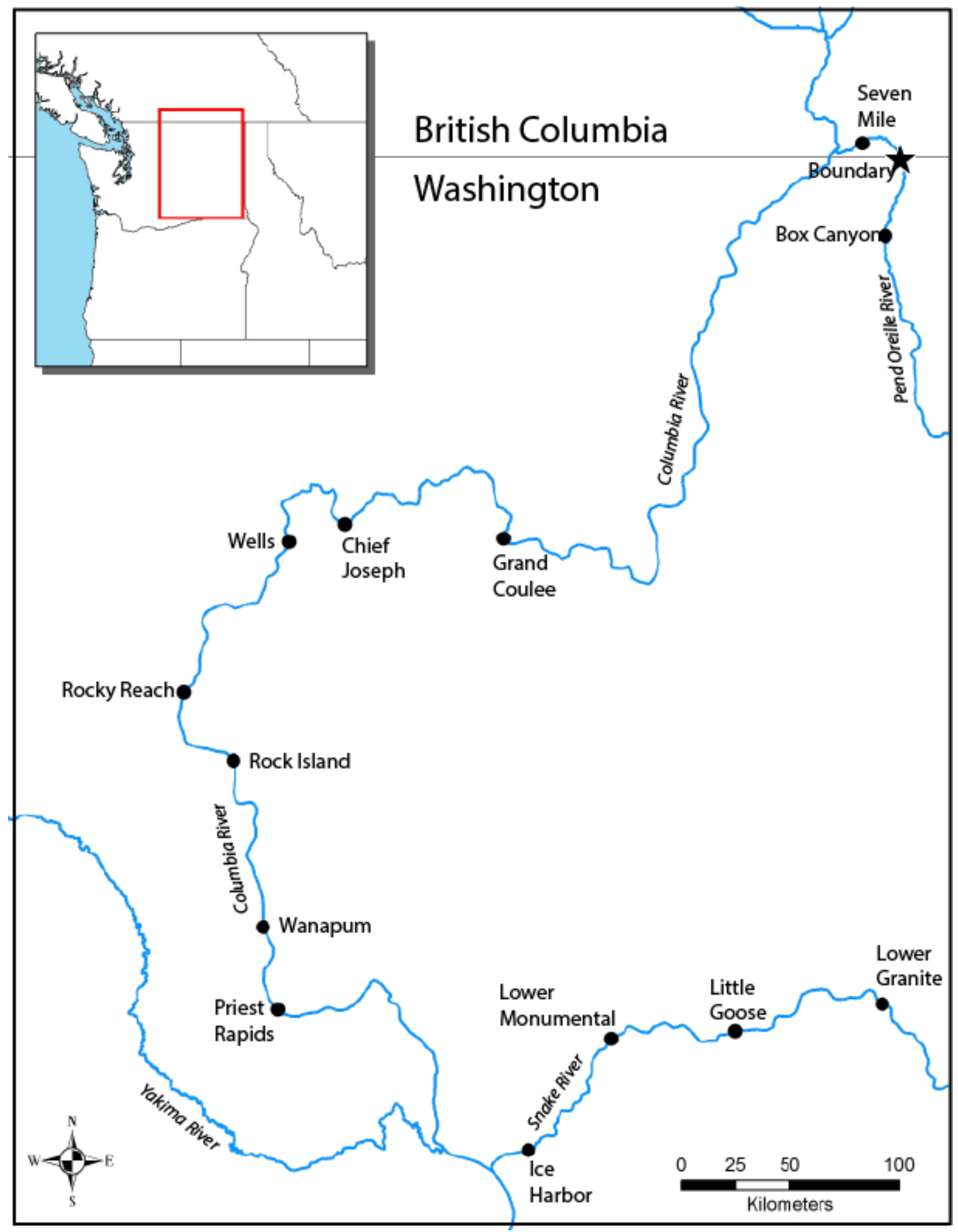

Figure 1. Location of Boundary Dam on the Pend Oreille River in Washington State. 


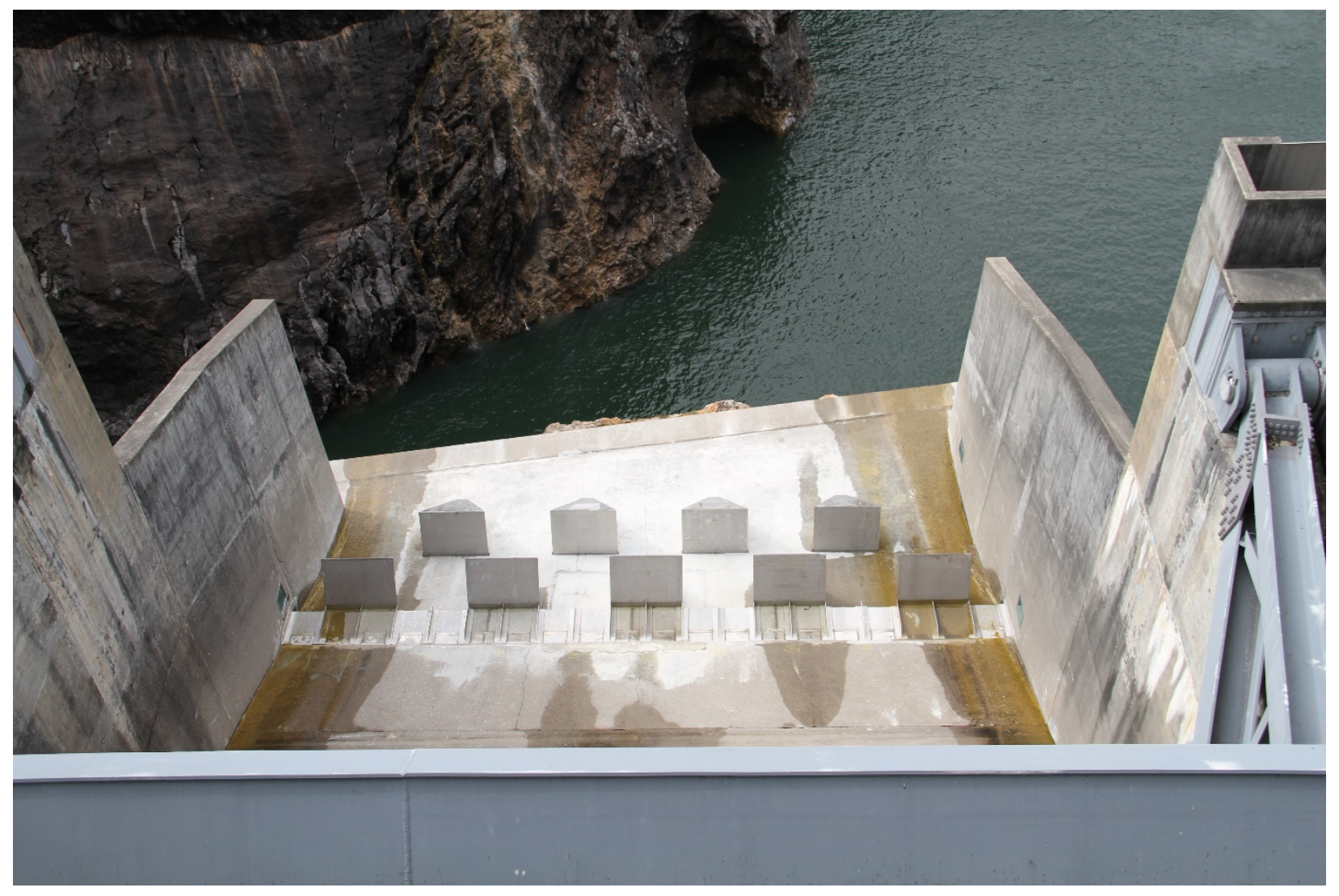

Figure 2. Installed Baffle-blocks at Boundary Dam. 


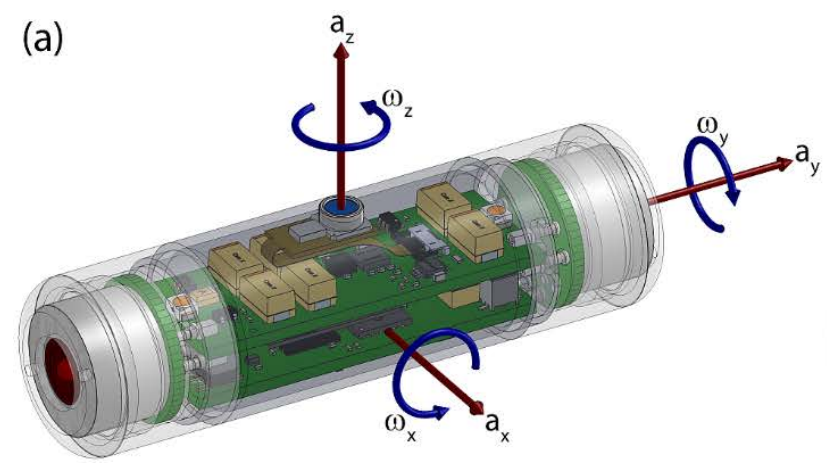

(b)

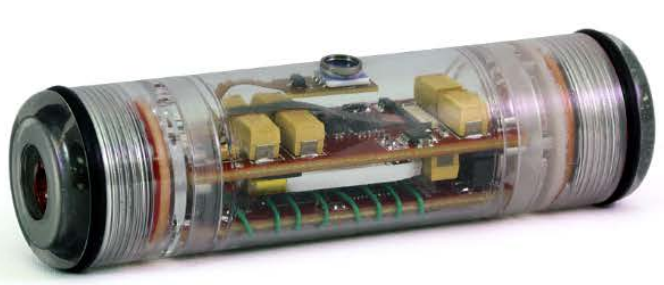

Figure 3. The AutonomousSensor Fish Device: (a) CAD drawing and (b) Photograph 

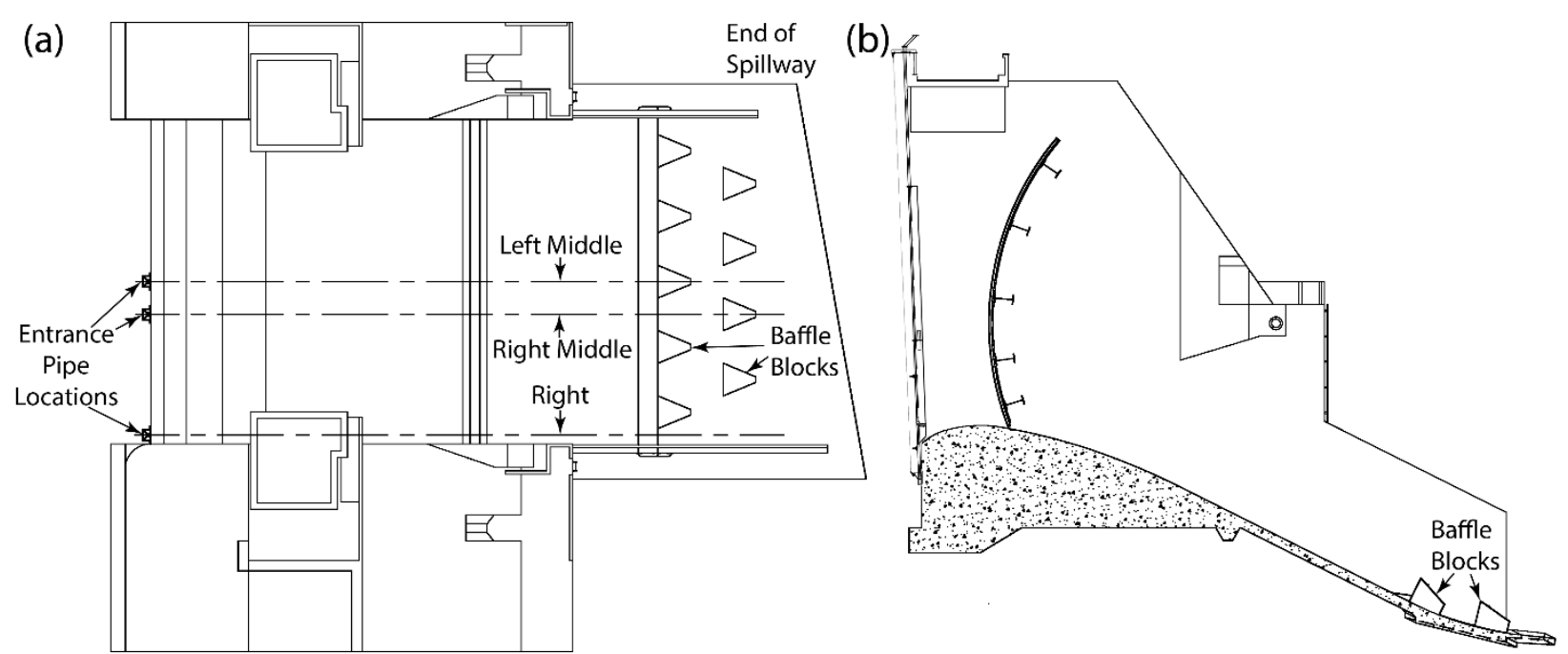

Figure 4. Location of Sensor Fish Lateral Release Positions.(a) Overhead view of the spillway; (b) Vertical cross-section of spillway. 

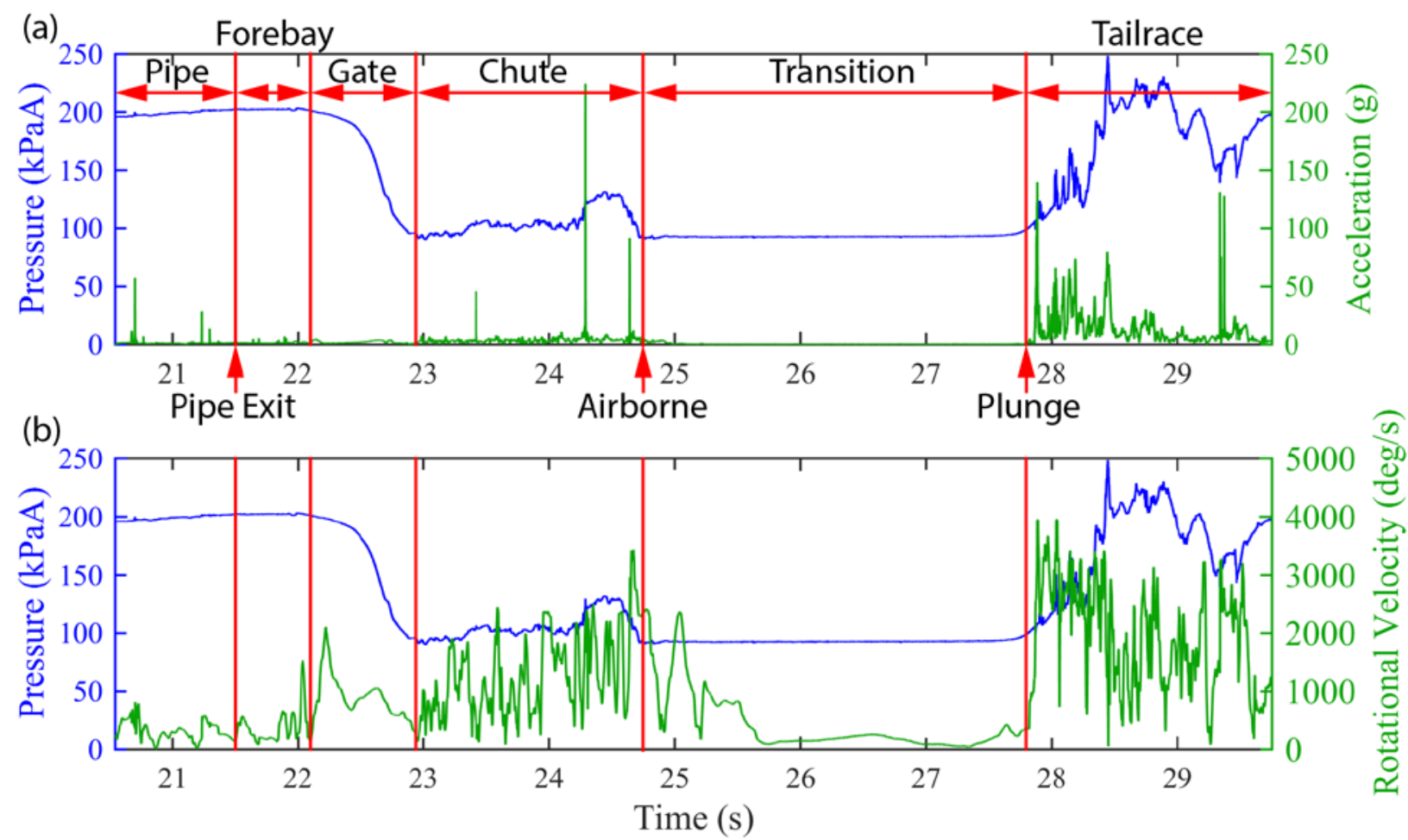

Figure 5. Example of Sensor Fish Data Showing the Approximate Locations of Major Timing Marks DuringBaseline Passage (i.e., prior to baffle block installation).(a) Absolute pressure (blue) and acceleration magnitude (green); (b) Absolute pressure (blue) and rotational velocity magnitude (green). The Sensor Fish data was collected on July 20, 2014 at 7 pm from the Left Middle location. 

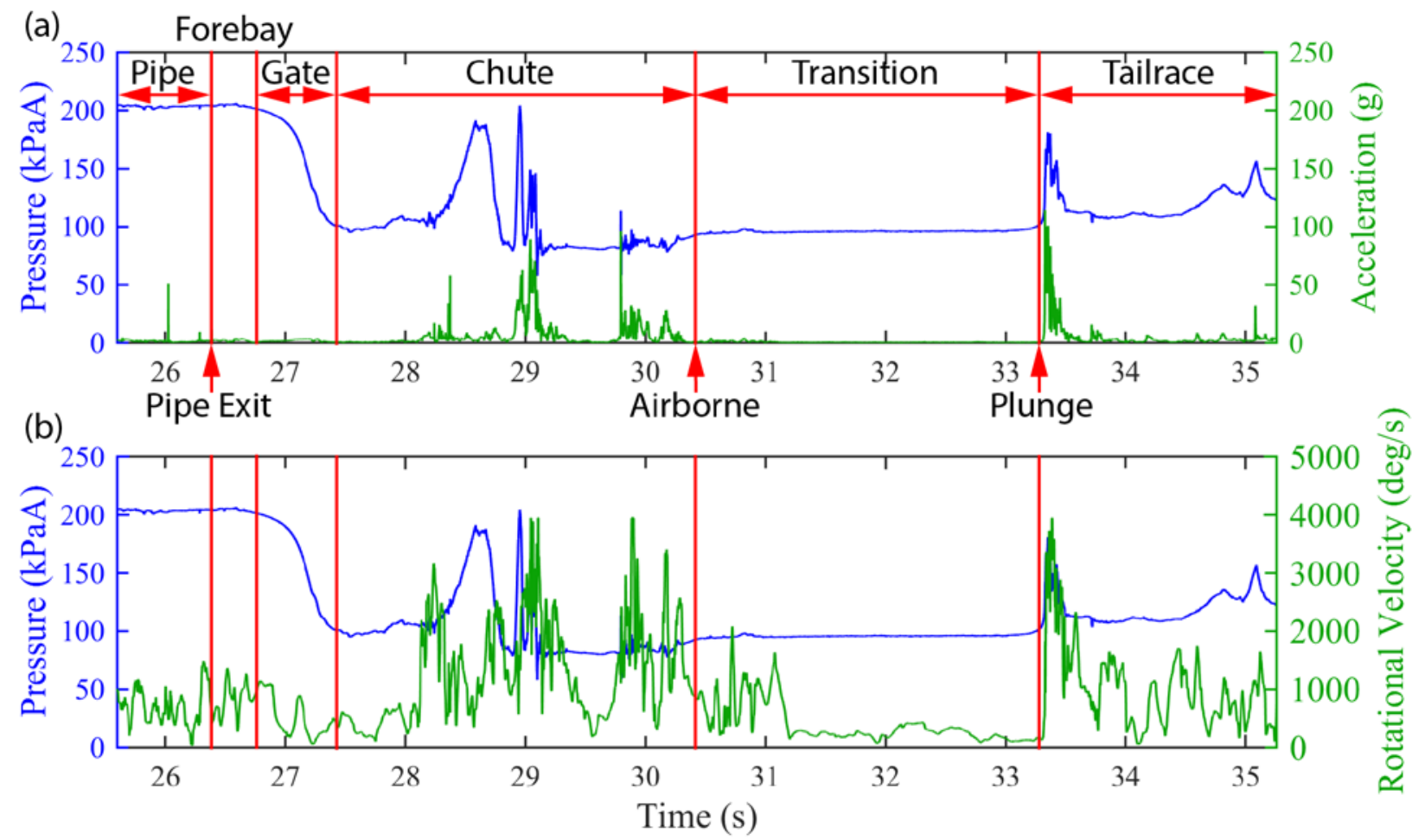

Figure 6. Example of Sensor Fish Data Showing the Approximate Locations of Major Timing Marks during Post-Modification Passage (i.e., after baffle block installation). (a) Absolute pressure (blue) and acceleration magnitude(green); (b) Absolute pressure (blue) and rotational velocity magnitude(green). The Sensor Fish data was collected on March 28, 2015 at 6 pm from the Right Middle location. 


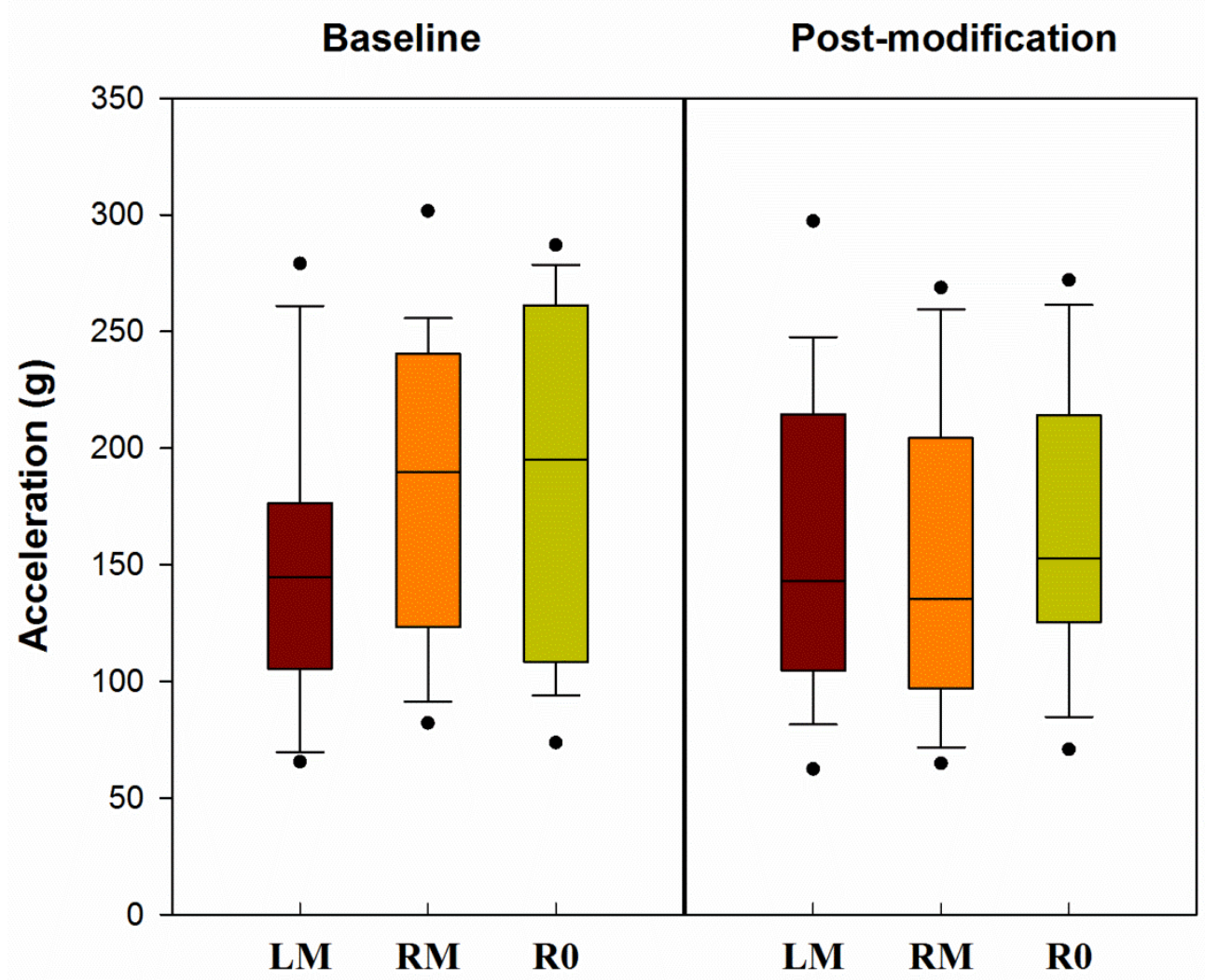

Figure 7. Sensor Fish Impact Magnitudes upon Entry to the Tailrace. Three lateral positions are evaluated: Left Middle (LM), Right Middle (RM), and Right (R0). 


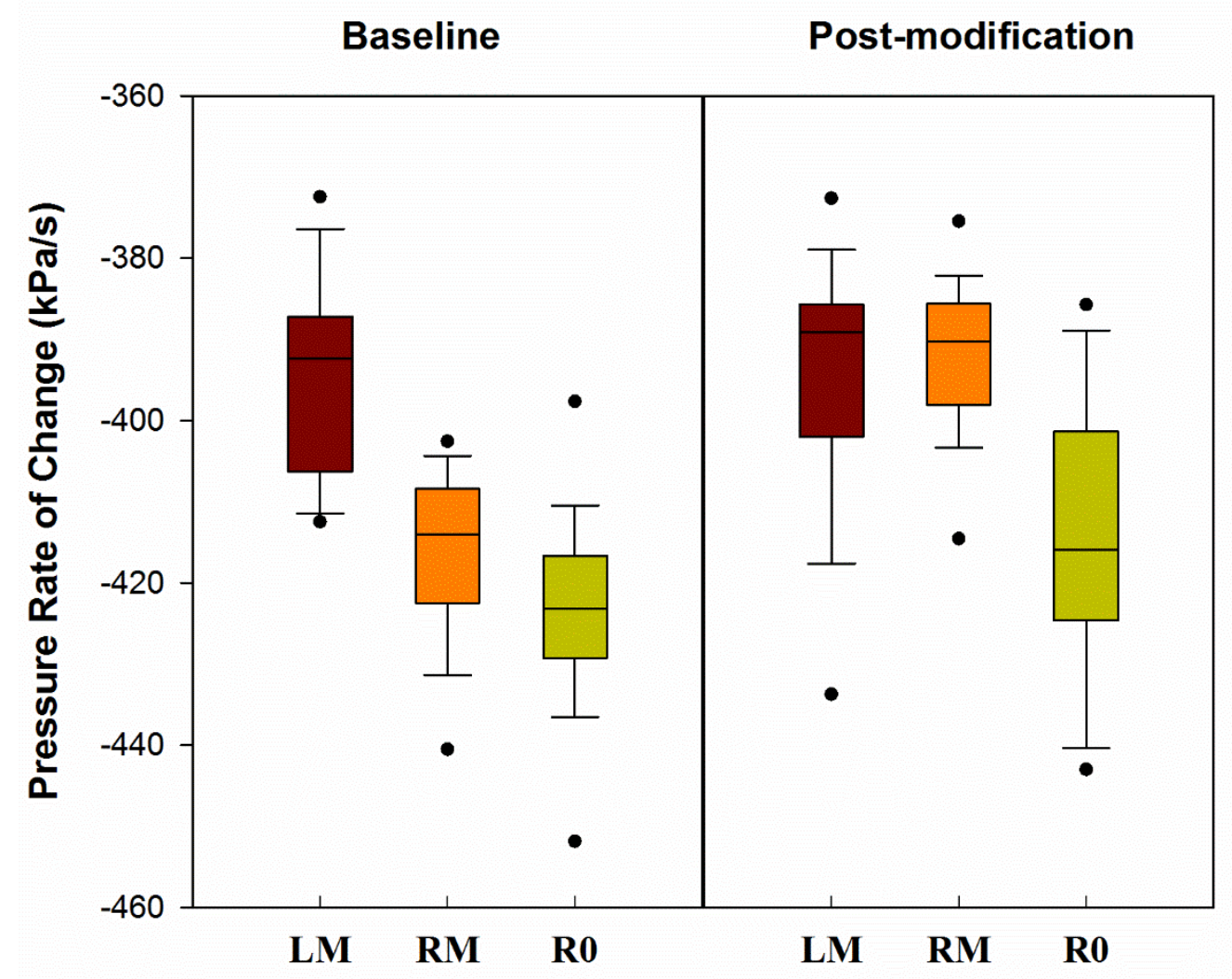

Figure 8.Pressure Rate of Change for Passage under the Gate. Three lateral positions are evaluated: Left Middle (LM), Right Middle (RM), and Right (R0). 

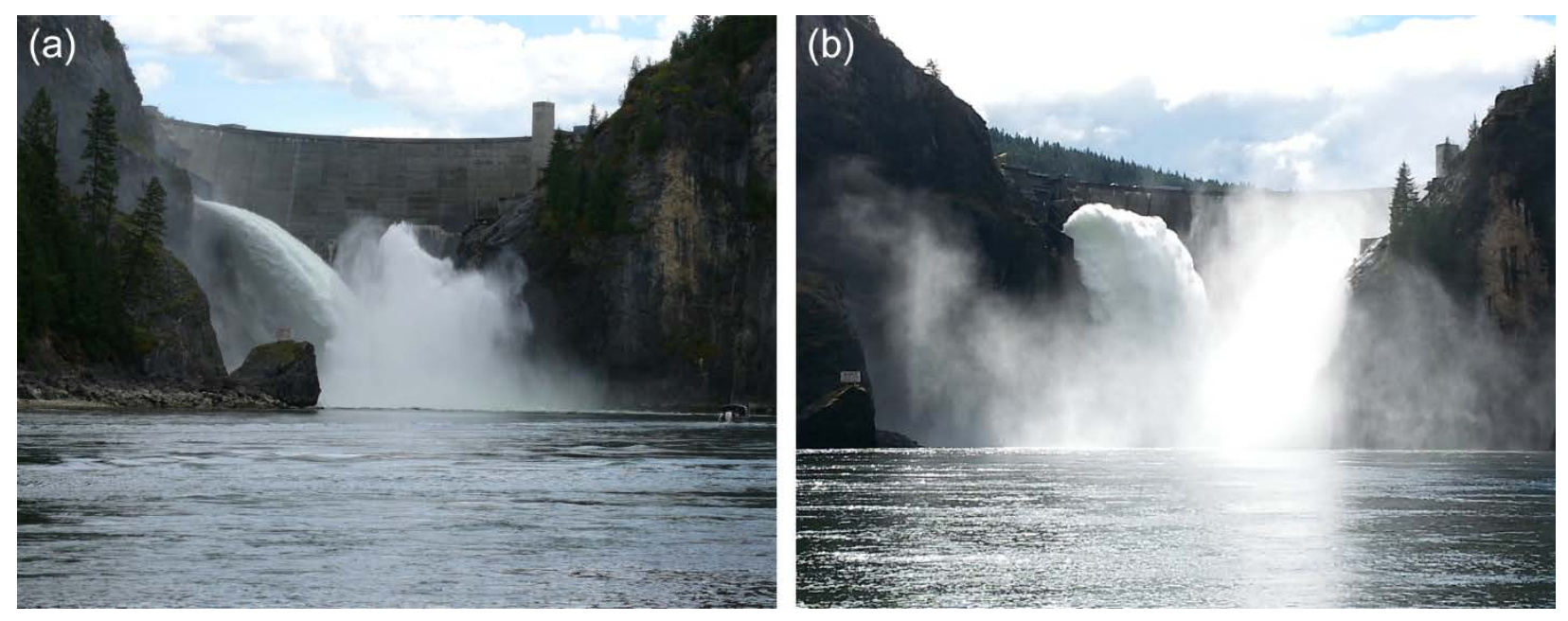

Figure 9.Spill Discharge at Boundary Dam:(a) On July 20, 2014 at 1:26 PM,prior to baffle block construction;(b)On March 28, 2015 at 10:32 AM,following baffle block construction (b). Following construction of the baffle blocks the flow jet was noticeably disrupted, potentially disrupting the plunge depth. 
Table 1. Number of Sensor Fish Releases by Study Treatment

\begin{tabular}{ccccc}
\hline \multirow{2}{*}{ Location } & Study & $\begin{array}{c}\text { Discharge } \\
\left(\mathrm{m}^{3} / \mathrm{s}\right)\end{array}$ & $\begin{array}{c}\text { Mean Forebay } \\
\text { Elevation (m MSL) }\end{array}$ & Sample size \\
\hline \multirow{2}{*}{ Left Middle } & Baseline & 283 & 605 & 13 \\
& Post-Modification & 340 & 605 & 32 \\
\multirow{2}{*}{ Right } & Baseline & 283 & 605 & 17 \\
& Post-Modification & 340 & 605 & 22 \\
& Baseline & 283 & 605 & 18 \\
Right Middle & Post-Modification & 340 & 605 & 27 \\
& & & & \\
\hline
\end{tabular}

Table. 2 Mean Sensor Fish Passage Time for Each Passage Region

\begin{tabular}{|c|c|c|c|c|c|}
\hline Location & Study & Entrance & Gate to & Chute to & Transition to \\
\hline & & to Gate (s) & Chute (s) & Transition (s) & Tailrace (s) \\
\hline \multirow{3}{*}{ Left Middle } & Baseline & 0.7 & 0.8 & 1.8 & 3.0 \\
\hline & & & & & \\
\hline & Post-Modification & 0.2 & 0.7 & 2.6 & 2.6 \\
\hline \multirow{3}{*}{ Right } & Baseline & 1.0 & 0.8 & 1.5 & 3.0 \\
\hline & & & & & \\
\hline & Post-Modification & 0.3 & 0.6 & 2.6 & 2.5 \\
\hline \multirow{3}{*}{ Right Middle } & Baseline & 0.7 & 0.8 & 1.7 & 3.0 \\
\hline & & & & & \\
\hline & Post-Modification & 0.3 & 0.7 & 2.9 & 2.6 \\
\hline
\end{tabular}


Table 3.Number of Sensor Fish Releases with at Least One Severe Eventby Treatment

\begin{tabular}{|c|c|c|c|c|c|c|c|c|}
\hline \multirow[b]{2}{*}{ Location } & \multirow[b]{2}{*}{ Study } & \multirow{2}{*}{$\begin{array}{l}\text { Valid } \\
\text { Releases }\end{array}$} & \multicolumn{3}{|c|}{ Chute } & \multicolumn{3}{|c|}{ Tailrace } \\
\hline & & & Strike & Shear & Total & Strike & Shear & Total \\
\hline \multirow{4}{*}{$\begin{array}{c}\text { Left } \\
\text { Middle }\end{array}$} & \multirow{2}{*}{ Baseline } & \multirow{2}{*}{13} & 5 & 0 & 5 & 9 & 5 & 11 \\
\hline & & & $38 \%$ & $0 \%$ & $38 \%$ & $69 \%$ & $38 \%$ & $85 \%$ \\
\hline & Post- & \multirow{2}{*}{32} & 18 & 11 & 20 & 24 & 8 & 27 \\
\hline & Modification & & $56 \%$ & $34 \%$ & $63 \%$ & $75 \%$ & $25 \%$ & $84 \%$ \\
\hline \multirow{4}{*}{ Right } & \multirow[b]{2}{*}{ Baseline } & \multirow[b]{2}{*}{17} & 0 & 0 & 0 & 16 & 2 & 16 \\
\hline & & & $0 \%$ & $0 \%$ & $0 \%$ & $94 \%$ & $12 \%$ & $94 \%$ \\
\hline & Post- & \multirow[b]{2}{*}{22} & 10 & 7 & 12 & 19 & 6 & 20 \\
\hline & Modification & & $45 \%$ & $32 \%$ & $55 \%$ & $86 \%$ & $27 \%$ & $91 \%$ \\
\hline \multirow{4}{*}{$\begin{array}{l}\text { Right } \\
\text { Middle }\end{array}$} & \multirow{2}{*}{ Baseline } & \multirow{2}{*}{18} & 6 & 0 & 6 & 15 & 5 & 15 \\
\hline & & & $33 \%$ & $0 \%$ & $33 \%$ & $83 \%$ & $28 \%$ & $83 \%$ \\
\hline & \multirow{2}{*}{$\begin{array}{l}\text { Post- } \\
\text { Modification }\end{array}$} & \multirow{2}{*}{27} & 9 & 4 & 9 & 22 & 7 & 22 \\
\hline & & & $33 \%$ & $15 \%$ & $33 \%$ & $81 \%$ & $26 \%$ & $81 \%$ \\
\hline
\end{tabular}

Table 4. Sensor Fish Significant Acceleration Events by Treatment

\begin{tabular}{|c|c|c|c|c|c|c|c|}
\hline & & \multicolumn{3}{|c|}{ Chute } & \multicolumn{3}{|c|}{ Tailrace } \\
\hline & & $\begin{array}{c}\text { Left } \\
\text { Middle }\end{array}$ & Right & $\begin{array}{c}\text { Right } \\
\text { Middle }\end{array}$ & $\begin{array}{c}\text { Left } \\
\text { Middle }\end{array}$ & Right & $\begin{array}{c}\text { Right } \\
\text { Middle }\end{array}$ \\
\hline \multirow{3}{*}{ Baseline } & Mean & 159 & -- & 164 & 172 & 199 & 202 \\
\hline & Maximum & 224 & -- & 221 & 279 & 287 & 302 \\
\hline & Minimum & 118 & -- & 97 & 129 & 99 & 96 \\
\hline \multirow{3}{*}{ Post-Mod } & Mean & 186 & 182 & 188 & 178 & 173 & 173 \\
\hline & Maximum & 245 & 311 & 324 & 310 & 272 & 274 \\
\hline & Minimum & 100 & 104 & 96 & 101 & 105 & 96 \\
\hline
\end{tabular}


Table. 5. Sensor Fish Depths Attained upon Entry into Tailrace

\begin{tabular}{|c|c|c|c|c|c|c|}
\hline Location & Study & $\begin{array}{c}\text { Valid } \\
\text { Releases }\end{array}$ & $\begin{array}{l}\text { Mean } \\
\text { Depth } \\
(\mathrm{m})\end{array}$ & $\begin{array}{l}\text { Depth } \\
\text { SE } \\
\text { (m) }\end{array}$ & $\begin{array}{l}\text { Minimum } \\
\text { Depth } \\
\text { (m) }\end{array}$ & $\begin{array}{l}\text { Maximum } \\
\text { Depth } \\
\text { (m) }\end{array}$ \\
\hline \multirow{2}{*}{$\begin{array}{l}\text { Left } \\
\text { Middle }\end{array}$} & Baseline & 13 & 16.3 & 2.5 & 3.2 & 37.0 \\
\hline & Post-Modification & 32 & 11.6 & 0.8 & 4.4 & 23.1 \\
\hline \multirow{3}{*}{ Right } & Baseline & 17 & 8.7 & 1.4 & 1.3 & 24.8 \\
\hline & & & & & & \\
\hline & Post-Modification & 22 & 10.1 & 0.7 & 2.8 & 16.5 \\
\hline \multirow{2}{*}{$\begin{array}{l}\text { Right } \\
\text { Middle }\end{array}$} & Baseline & 18 & 20.4 & 2.5 & 3.4 & 41.0 \\
\hline & Post-Modification & 27 & 10.2 & 0.9 & 2.9 & 22.4 \\
\hline
\end{tabular}

